\title{
POLY(HYDROXYBUTYRATE-CO- HYDROXYVALERATE) MICRONIZATION BY SOLUTION ENHANCED DISPERSION BY SUPERCRITICAL FLUIDS TECHNIQUE
}

\author{
G. P. S. Aguiar ${ }^{1 *}$, C. D. Magro ${ }^{1}$, J. V. Oliveira ${ }^{1}$ and M. Lanza ${ }^{1}$ \\ ${ }^{1}$ Department of Chemical and Food Engineering, UFSC, Florianópolis, SC, Brazil.
}

(Submitted: October 1, 2017 ; Revised: December 25, 2017 ; Accepted: January 8, 2018)

\begin{abstract}
Poly(3-hydroxybutyrate-co-3-hydroxyvalerate) (PHBV) is a biodegradable polymer used for a wide range of applications, especially in biomedical and food industry, for which bioactive compound encapsulation is noteworthy. This work aimed to micronize PHBV by Solution Enhanced Dispersion by Supercritical Fluids technique and evaluate possible changes in polymer crystallinity. A $2^{3}$ Central Composite Design with 3 central points was used to analyze the influence of pressure, temperature and PHBV concentration on particle size produced. Micronized particles were mostly spherical with sizes from 210 to $720 \mathrm{~nm}$, and free of organic solvents. PHBV crystallinity degree was approximately $20 \%$ higher when polymer was processed at $8 \mathrm{MPa}$ compared to that processed at 10 and $12 \mathrm{MPa}$, as well as to the raw polymer. Results suggest versatility in PHBV application according to SEDS process parameters and the possibility of its use in drug delivery systems.

Keywords: PHBV; SEDS; Biopolymer; Submicron particles; Supercritical $\mathrm{CO}_{2}$.
\end{abstract}

\section{INTRODUCTION}

Polymers have been used for many applications in our society, in different industrial fields. The use of biodegradable polymers has attracted attention from scientists and industry due to the structural similarity with synthetic polymers from non-renewable sources but lower environmental impact generated. Among the biodegradable polymers, polyhydoxyalkanoates (PHAs) are noteworthy due to the versatility in the production of different copolymers. PHAs production is based on microbiological conversion of alcaligenes bacteria, which consume the carbon source from growth medium and transform it into polyesters stored as intracellular granules. Subsequently, the polyesters are obtained in the final form by downstream processes (extraction, separation and purification). Variations in the length and composition of the polymeric chain allow a wide potential of applications (Oliveira et al.,
2006). Furthermore, toxicity analyses have shown that monomers of PHAs may not be toxic to humans, but can even provide some therapeutical or nutritional benefits (Chen and $\mathrm{Wu}, 2005)$.

Poly(hydroxybutyrate) (PHB) and its copolymer poly(hydroxybutyrate-co-hydroxyvalerate) (PHBV) are thermoplastic, from renewable sources, biodegradable, compostable and biocompatible polymers of the PHAs group. They present properties similar to polypropylene such as melting point, degree of crystallinity and glass transition temperature. Besides, PHB and PHBV are applicable for a wide range of products, including disposable materials, packages, medical artifacts for human or veterinary use, automobile industry products, among others. The introduction of hydroxyvalerate units along the PHB polymeric chains aims to reduce the crystallinity degree $(55-70 \%)$, providing more flexibility, ductility and elasticity compared to the homopolymers,

\footnotetext{
* Corresponding author: Tel.: +55 48 37214069; Fax: +55 48 37219687. E-mail address: geanpablo@gmail.com (Gean Pablo).
} 
consequently improving its applications (Brunel et al., 2014).

One of the greatest advantages of PHB and PHBV is that both present slow degradation rate, which make them potential materials for use in controled release systems, where size and morphology of the polymer matrix are of extreme importance in drug release and pharmacokinetics. In this context, the use of micro- and nanoparticles comprise a very interesting approach, since these systems facilitate the diffusion through biological barriers (Costa et al., 2007).

Supercritical technologies present several advantages in particle formation due to the high quality of products obtained, reduced use of organic solvents and high control of process parameters (Yeo and Kiran, 2005). Moreover, it has been related that supercritical fluids, especially supercritical carbon dioxide, promote certain changes in polymeric structure, such as decrease of crystallinity, melting temperature and crystallization temperature. These phenomena are caused by intermolecular interactions between $\mathrm{CO}_{2}$ and the polymer dissolved in the system (Cocero et al., 2009).

According to Fleming and Kazarian (2005), supercritical $\mathrm{CO}_{2}$ is able to reduce polymer viscosity since $\mathrm{CO}_{2}$ absorption changes the matrix by its swelling and volume increase. In this way, the supercritical fluid acts increasing molecular mobility as well as the distance between chains. Generally, this effect also causes a reduction in the polymer glass transition.

The low solubility of polymers in carbon dioxide and their relatively high solubility in organic solvents provide favorable conditions to process PHBV employing techniques that make use of supercritical fluid as antisolvent. In fact, PHBV microparticle precipitation by a Supercritical Antisolvent technique (SAS) has already been studied (Cardoso et al., 2015; Costa et al., 2007). Submicron or nanoparticles might be obtained employing the Solution Enhanced Dispersion by Supercritical Fluids technique (SEDS), and appears to be more interesting since an effective administration of a compound requires particles with 0.1 to $0.3 \mu \mathrm{m}$ for intravenous administration and between 0.1 and $100 \mu \mathrm{m}$ for oral administration (Kalani and Yunus, 2011). The main difference of SAS and SEDS is the injection form of the solution through a coaxial nozzle, which favors obtaining smaller particles. Franceschi et al. (2008) and Priamo et al. (2010) performed PHBV precipitation by SEDS in order to encapsulate $\beta$-carotene, obtaining submicron particles, although other characteristics of the polymer were not evaluated.

In this context, this work aimed to micronize PHBV by the SEDS technique using supercritical carbon dioxide as antisolvent, as well as to characterize the precipitated particles regarding morphology, mean particle size and crystallinity degree, evaluating possible changes in crystallinity, melting temperature and crystallinity temperature. It is worth mentioning that this work is part of a broader project aiming at the co-precipitation of PHBV with several bioactive compounds in order to improve their solubility and bioavailability, protect them from external agents and also promote their controlled release. In face of that, this work also pursuits the best operation parameters towards producing smaller PHBV particle size.

\section{MATERIALS AND METHODS}

\section{Materials}

Poly(3-hydroxybutyrate-co-3-hydroxyvalerate) with average molar mass $(M)$ of $196,000 \mathrm{~g} \cdot \mathrm{mol}^{-1}$ and poly dispersity index $(D)$ of 1.85 was kindly provided by $\mathrm{PHB}$ Industrial $\mathrm{S} / \mathrm{A}$ (Brazil) and was subjected to further purification following the methodology of Loss et al. (2016). The solvents dichloromethane (99.5\%) and acetone (99.5\%) were purchased from Vetec (Sigma-Aldrich), while the anti-solvent carbon dioxide (99.9\% in liquid phase) was provided by White Martins S.A.

\section{Solution Enhanced Dispersion by Supercritical Fluids Technique}

The experimental apparatus and procedure used for PHBV micronization by the SEDS technique were previously described in details (Boschetto et al., 2013; Franceschi et al., 2008). Briefly, the experimental apparatus consists of a high pressure vessel used as precipitation chamber with internal volume of 600 $\mathrm{mL}$ and internal diameter of $8 \mathrm{~cm}$; two syringe pumps for $\mathrm{CO}_{2}$ displacement (ISCO, Model 500D), operated independently by a set of ball valves (Swagelok, Model SS-83KS4), and a digital HPLC liquid pump (Acuflow, Series III) used for organic solution delivery. A schematic diagram of the processing apparatus was recently presented by Aguiar et al. (2017) and Dal Magro et al. (2017).

The parameters used were based on the works of Boschetto et al. (2013), Franceschi et al. (2009, 2008) and Priamo et al. (2010) with PHBV concentration of 4, 12 and $20 \mathrm{mg} \cdot \mathrm{mL}^{-1}$, temperature of 35,40 and 45 ${ }^{\circ} \mathrm{C}$, operating pressure of 8,10 and $12 \mathrm{MPa}$, solution flow rate of $1 \mathrm{~mL} \cdot \mathrm{min}^{-1}$ and anti-solvent flow rate of $20 \mathrm{~mL} \cdot \mathrm{min}^{-1}$ (at $20 \mathrm{MPa}$ and $5{ }^{\circ} \mathrm{C}$ ). A $2^{3}$ Central Composite Design (CCD) with three central points was used to evaluate the influence of variables pressure, temperature and PHBV concentration on particle size obtained and all CCD data were analyzed with a confidence level of $95 \%$. 
First, PHBV was solubilized in dichloromethane $(60 \%)$ and then the volume was completed with acetone (40\%). This solvent mixture was used having in mind the idea of co-precipitating PHBV with several bioactive compounds, which are not soluble in pure dichloromethane, but are soluble in dichloromethaneacetone mixture. Subsequently, $\mathrm{CO}_{2}$ was pumped to fill the precipitation chamber up to the desired pressure. Anti-solvent flow rate was controlled by setting needle valves, and monitored by the syringe pump. When temperature (controlled by a thermostatic bath), pressure and anti-solvent flow rate were stabilized, organic solution was added through a capillary tubing. Pressure for solution spray into the precipitator was controlled by back pressure regulator manipulation and monitored by the liquid pump. After solution addition $(25 \mathrm{~mL}), \mathrm{CO}_{2}$ was continuous flowed for 50 min in order to dry the precipitated particles inside the chamber. The precipitation chamber was slowly depressurized to atmospheric pressure and particles were collected and stored at appropriate conditions for subsequent analysis.

\section{Morphology and Determination of Particle Size}

Morphology of PHBV particles was analyzed in a scanning electron microscope (SEM - JEOL JSM6390LV, United States). Through the micrographs, particle size was determined using the software Size Meter (version 1.1) (Aguiar et al., 2018; Machado Jr et al., 2014). This method consists in evaluating the measures of length and thickness (highest characteristic measurement) of approximately 600 to 700 particles for each experimental condition evaluated. Therefore, average particle size, standard deviation and variation coefficient (VC) were determined and used as statistical tools to express the data variability.

\section{Identification and Quantification of Residual Solvent}

Gas chromatography was used to identify residual solvent in PHBV particles through GC model 5975C Inert MSD brand Agilent Technologies, coupled with mass spectrometer (GC-MS) in a headspace vial with a DB624 - $30 \mathrm{~m} \times 0.45 \mathrm{~mm} \times 2.55 \mu \mathrm{m}$ column. Subsequently, quantification of residual solvent was investigated by gas chromatography - flame ionization detector (GC-FID) using the same operation conditions as in the GC-MS (Aguiar et al., 2016).

\section{Fourier Transform Infrared Spectroscopy (FTIR)}

In order to evaluate possible changes in PHBV structure due to the SEDS process, measurements of Fourier Transform Infrared Spectroscopy (FTIR) were made in an Agilent Technologies - Cary 600 Series FTIR Spectrometer, grinding approximately $1 \mathrm{mg}$ of particles with $\mathrm{KBr}$ and pressing into a pellet for FTIR characterization within the wavenumber range of 400 to $4000 \mathrm{~cm}^{-1}$.

\section{Calorimetric Profiles with Differential Scanning Calorimetry (DSC)}

Aiming to estimate modifications in the crystallinity degree, melting temperature and crystallization temperature caused by the supercritical process, thermal analyses of PHBV particles, raw and purified PHBV were conducted under nitrogen atmosphere in a differential scanning calorimeter (Jade-DSC - Perkin Elmer). Samples were heated from -30 to $300{ }^{\circ} \mathrm{C}$ at a rate of $10^{\circ} \mathrm{C} \cdot \mathrm{min}^{-1}$ (first heating) and held at the final temperature for $1 \mathrm{~min}$ to eliminate the thermal history applied to the samples. After cooling to $-30{ }^{\circ} \mathrm{C}$, they were reheated to $300^{\circ} \mathrm{C}$ at a rate of $10^{\circ} \mathrm{C} \cdot \mathrm{min}^{-1}$ (second heating). All tests were carried out with a nitrogen flow rate of $50 \mathrm{~mL} \cdot \mathrm{min}^{-1}$. Thermal parameters such as melting enthalpy $\left(\Delta \mathrm{H}_{\mathrm{m}}\right)$, melting temperature $\left(\mathrm{T}_{\mathrm{m}}\right)$ and cold-crystallization temperature $\left(\mathrm{T}_{\mathrm{c}}\right)$ were obtained from the second run. From the values of $\Delta \mathrm{H}_{\mathrm{m}}$, polymer crystallinity degree $(\% \mathrm{C})$ was calculated according to the following expression:

$\% \mathrm{C}=\frac{\Delta \mathrm{H}_{\mathrm{M}}}{\Delta \mathrm{H}_{\mathrm{M} 100 \%}} \times 100$

where $\Delta \mathrm{H}_{\mathrm{m} 100 \%}$ is the theoretical enthalpy of hypothetically $100 \%$ crystalline polymer, which is 146 $\mathrm{J} \cdot \mathrm{g}^{-1}$ (Cheng and Sun, 2009).

\section{RESULTS AND DISCUSSION}

\section{Particle Characterization}

PHBV presents great potential as drug carrier due to its biocompatibility, bioabsorption and slow degradation rate, compared to other biopolymers. For this purpose, morphology and particle size exert great influence on the interaction between particles and physiological environment (Walkey and Chan, 2012). Morphology of PHBV micronized in all experimental conditions was analyzed by scanning electron microscopy and is presented in Figure 1.

In general, all experimental conditions resulted in PHBV particles with morphology predominantly spherical, except for run 8 , where irregular, fibrous structures similar to the raw copolymer, besides smaller spherical structures, can be observed. This can occur due to the solution being more saturated and higher temperature, which hinders the process of 


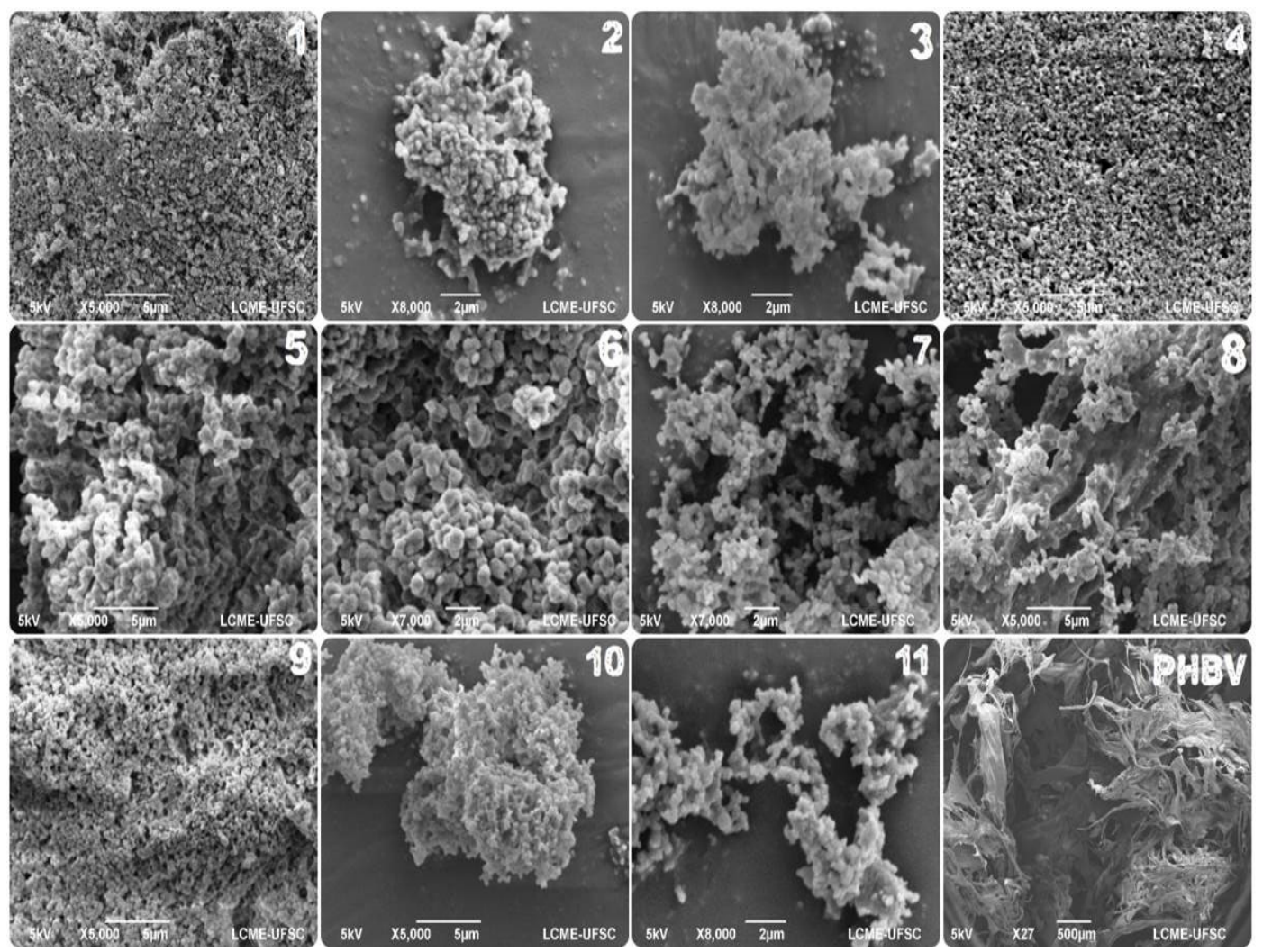

Figure 1. Morphology of PHBV micronized in the runs 1 to 11 . Experimental conditions: $1\left(4 \mathrm{mg} \cdot \mathrm{mL}^{-1}, 8 \mathrm{MPa}\right.$ and $\left.35^{\circ} \mathrm{C}\right), 2\left(20 \mathrm{mg} \cdot \mathrm{mL}^{-1}, 8 \mathrm{MPa}\right.$ and $\left.35^{\circ} \mathrm{C}\right), 3\left(4 \mathrm{mg} \cdot \mathrm{mL}^{-1}, 12 \mathrm{MPa}\right.$ and $\left.35^{\circ} \mathrm{C}\right), 4\left(20 \mathrm{mg} \cdot \mathrm{mL}^{-1}, 12 \mathrm{MPa}\right.$ and $\left.35^{\circ} \mathrm{C}\right), 5$ $\left(4 \mathrm{mg} \cdot \mathrm{mL}^{-1}, 8 \mathrm{MPa}\right.$ and $\left.45^{\circ} \mathrm{C}\right), 6\left(20 \mathrm{mg} \cdot \mathrm{mL}^{-1}, 8 \mathrm{MPa}\right.$ and $\left.45^{\circ} \mathrm{C}\right), 7\left(4 \mathrm{mg} \cdot \mathrm{mL}^{-1}, 12 \mathrm{MPa}\right.$ and $\left.45^{\circ} \mathrm{C}\right), 8\left(20 \mathrm{mg} \cdot \mathrm{mL}^{-1}\right.$, $12 \mathrm{MPa}$ and $\left.45^{\circ} \mathrm{C}\right), 9,10$ and $11\left(12 \mathrm{mg} \cdot \mathrm{mL}^{-1}, 10 \mathrm{MPa}\right.$ and $\left.40^{\circ} \mathrm{C}\right)$.

nucleation of the polymer altering its structure. Values of mean particle size, standard deviation and variation coefficient obtained from the $2^{3} \mathrm{CCD}$ are shown in Table 1.

PHBV micronized particles showed mean sizes in the sub-micrometric range, from 210 to $720 \mathrm{~nm}$, with variation coefficients ranging from 24 to $43 \%$. Statistical analysis showed that temperature presented a significant positive effect on the mean particle size ( $95 \%$ confidence level), as shown in the Pareto chart of Figure 2. This effect can be observed comparing runs 1 to 4 (performed at $35^{\circ} \mathrm{C}$ ) with runs 5 to 11 (performed at 40 and $45^{\circ} \mathrm{C}$ ). Higher temperatures favor polymer dissolution, leading to a low level of agglomeration and crystal growth in the nucleation process, which leads to an increase in particle size (Aguiar et al., 2016; Cocero and Ferrero, 2002; Priamo et al., 2013). The use of lower temperatures is of course also important for encapsulation of bioactive compounds due to their thermosensitive nature.

On the other hand, the cross interaction between pressure and temperature presented a significant negative effect on particle size. This effect might be related to the interfacial tension between the organic solution and the supercritical antisolvent, as well as to enhancement in $\mathrm{CO}_{2}$ density with pressure increase.

Table 1. Results of $2^{3} \mathrm{CCD}$ experimental design of PHBV micronization.

\begin{tabular}{cccccc}
\hline Run & $\begin{array}{c}\text { Concentration } \\
\left(\mathbf{m g} \cdot \mathbf{m L}^{-1}\right)\end{array}$ & $\begin{array}{c}\text { Pressure } \\
(\mathbf{M P a})\end{array}$ & $\begin{array}{c}\text { Temperature } \\
\left(\mathbf{}^{\mathbf{C}} \mathbf{C}\right)\end{array}$ & $\begin{array}{c}\mathbf{D}_{\mathbf{p}} \pm \boldsymbol{\sigma} \\
(\boldsymbol{\mu m})\end{array}$ & $\mathbf{V C}$ \\
\hline 1 & $4(-1)$ & $8(-1)$ & $35(-1)$ & $0.21 \pm 0.07$ & 0.33 \\
2 & $20(1)$ & $8(-1)$ & $35(-1)$ & $0.24 \pm 0.07$ & 0.30 \\
3 & $4(-1)$ & $12(1)$ & $35(-1)$ & $0.37 \pm 0.16$ & 0.43 \\
4 & $20(1)$ & $12(1)$ & $35(-1)$ & $0.30 \pm 0.09$ & 0.30 \\
5 & $4(-1)$ & $8(-1)$ & $45(1)$ & $0.62 \pm 0.16$ & 0.26 \\
6 & $20(1)$ & $8(-1)$ & $45(1)$ & $0.72 \pm 0.23$ & 0.31 \\
7 & $4(-1)$ & $12(1)$ & $45(1)$ & $0.38 \pm 0.12$ & 0.33 \\
8 & $20(1)$ & $12(1)$ & $45(1)$ & $0.57 \pm 0.15$ & 0.26 \\
9 & $12(0)$ & $10(0)$ & $40(0)$ & $0.34 \pm 0.09$ & 0.28 \\
10 & $12(0)$ & $10(0)$ & $40(0)$ & $0.36 \pm 0.09$ & 0.25 \\
11 & $12(0)$ & $10(0)$ & $40(0)$ & $0.36 \pm 0.09$ & 0.24 \\
\hline
\end{tabular}




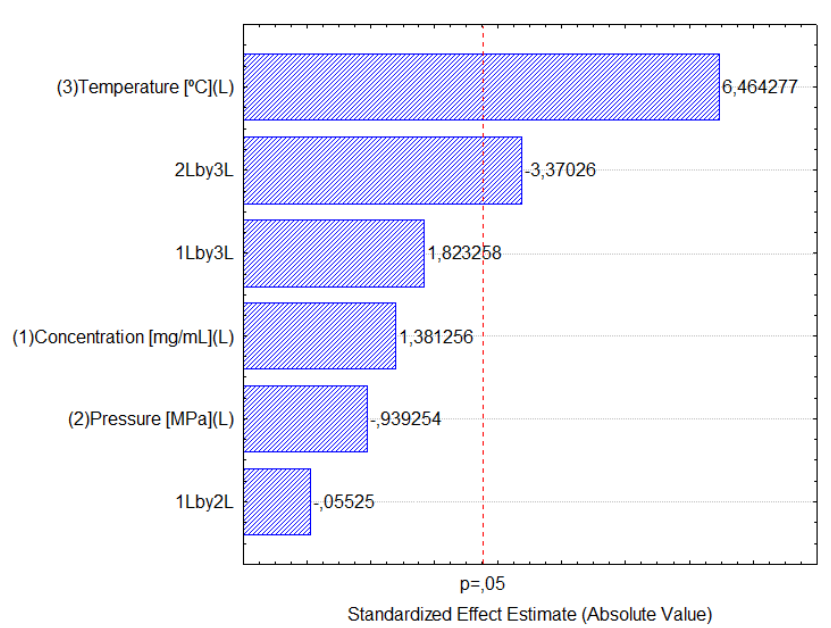

Figure 2. Pareto chart showing the effects of the micronization by SEDS on the mean particle size.

Therefore, the better dispersion of the polymeric solution in the supercritical antisolvent leads to a decrease in the droplet size and acceleration of mass transfer phenomena, causing a fast precipitation of the compound (Boutin et al., 2004; Chen et al., 2007).

\section{Identification and Quantification of Residual Solvent}

Residual solvent analysis performed by GC-MS and GC-FID showed the presence of $21.75 \mathrm{ppm}$ of dichloromethane in the particles, while the acetone residue was lower than the limit of the instrument used, i.e., $<1 \mathrm{ppm}$. Such results are in agreement with regulatory agencies - The National Agency for Sanitary Vigilance - ANVISA Brazil, Pharmacopoeia of the People's Republic of China, European Pharmacopoeia and International Conference on Harmonization (ICH), document Q3C (R5) from 2011, that establish the maximum concentration for human consumption at $600 \mathrm{ppm}$ for dichloromethane and $5000 \mathrm{ppm}$ for acetone (Aguiar et al., 2016, Dal Magro et al., 2017). Aguiar et al. (2016), using the SEDS technique in the micronization process of resveratrol, obtained residual solvent dichloromethane and acetone between 50-80 ppm. Therefore, values obtained for micronization of PHBV are very promising.

\section{Fourier Transform Infrared Spectroscopy (FTIR)}

PHBV particles obtained at different pressures (runs 2, 4 and 9) were analyzed by FTIR as well as the raw and purified copolymer and the results are presented in Figure 3. All samples showed characteristic band assignments in the same wavenumber range: bands at 2980 and $2933 \mathrm{~cm}^{-1}$ (numbers 1 and 2 in Figure

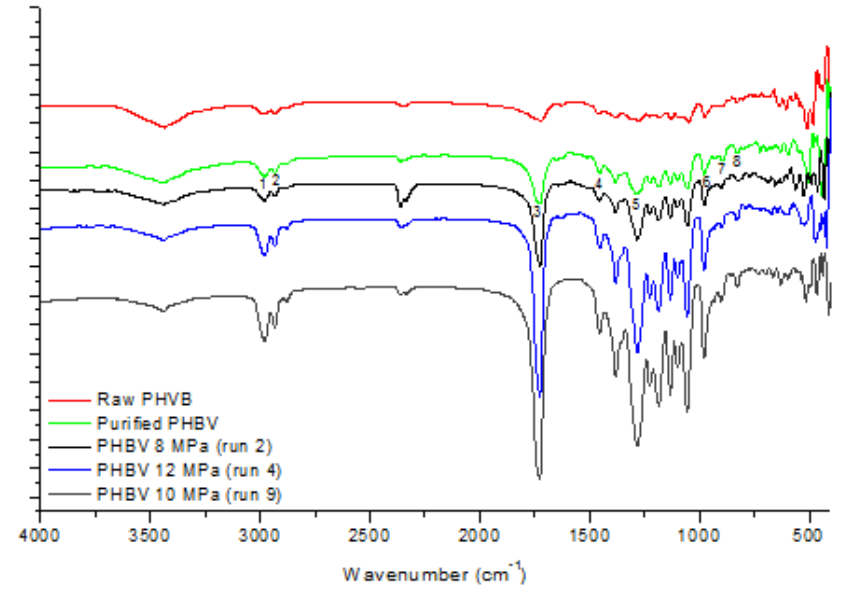

Figure 3. FTIR spectra of raw PHBV, purified PHBV and PHBV micronized in runs $2(8 \mathrm{MPa}, 20$ $\mathrm{mg} \cdot \mathrm{mL}^{-1}$ and $\left.35^{\circ} \mathrm{C}\right), 4\left(12 \mathrm{MPa}, 20 \mathrm{mg} \cdot \mathrm{mL}^{-1}\right.$ and 35 ${ }^{\circ} \mathrm{C}$ ) and $9\left(10 \mathrm{MPa}, 12 \mathrm{mg} \cdot \mathrm{mL}^{-1}\right.$ and $\left.40{ }^{\circ} \mathrm{C}\right) .1$ and 2: asymmetric and symmetric stretching vibration of $\mathrm{CH}_{3}$, respectively; 3 : $\mathrm{C}=\mathrm{O}$ stretching; 4: bending modes of $\mathrm{C}-\mathrm{H} ; 5:-\mathrm{C}-\mathrm{O}-\mathrm{C}-$ stretching vibration; 6,7 and $8: \mathrm{C}-\mathrm{C}$ stretching vibration.

3 , respectively) due to symmetric and asymmetric stretching vibration of $\mathrm{CH}_{3}$; a band at 1727 and its shoulder at $1754 \mathrm{~cm}^{-1}$ (number 3 in Figure 3) due to $\mathrm{C}=\mathrm{O}$ stretching, which are also related to crystalline and amorphous components in PHBV, respectively; bands at 1455 and $1285 \mathrm{~cm}^{-1}$ (numbers 4 and 5 in Figure 3 , respectively) corresponding to bending modes of the $\mathrm{C}-\mathrm{H}$ and the stretching vibration of $-\mathrm{C}-\mathrm{O}-\mathrm{C}-$, respectively, and crystalline bands at 977 , 900 and $829 \mathrm{~cm}^{-1}$ (numbers 6, 7 and 8 in Figure 3) corresponding to $\mathrm{C}-\mathrm{C}$ stretching vibration (Yu et al., 2014; Yu and Qin, 2014), indicating that no change occurred in polymer structure. It is possible to note the increase in the band intensity comparing purified to raw PHBV, as already expected. There was also an increase in intensity after the SEDS process for all experimental conditions, suggesting that PHBV might be in a slightly crystalline form after the SEDS process or purification of the polymer may have occurred by the process.

\section{Calorimetric Profiles and Evaluation of Crystallinity Degree}

Since the crystallinity exerts great influence on the physical properties of polymers, Differential Scanning Calorimetry was performed in order to estimate modifications in PHBV crystallinity degree eventually caused by the micronization process via SEDS. Figure 4 shows the DSC curves of PHBV micronized at 8, 10 and $12 \mathrm{MPa}$ (runs 2, 9 and 4, respectively), raw and purified polymer during first cooling and second 
Table 2. Values of glass transition temperature $\left(T_{p}\right)$, melting temperature $\left(T_{m}\right)$, crystallization temperature $\left(T_{c}\right)$, crystallization enthalpy $\left(\Delta \mathrm{H}_{\mathrm{c}}\right)$, melting enthalpy $\left(\Delta \mathrm{H}_{\mathrm{m}}\right)$ and crystallinity degree $(\% \mathrm{C})$ of raw PHBV, purified PHBV and PHBV micronized for runs $2\left(8 \mathrm{MPa}, 20 \mathrm{mg} \cdot \mathrm{mL}^{-1}\right.$ and $\left.35^{\circ} \mathrm{C}\right), 4\left(12 \mathrm{MPa}, 20 \mathrm{mg} \cdot \mathrm{mL}^{-1}\right.$ and $\left.35^{\circ} \mathrm{C}\right)$ and $9(10 \mathrm{MPa}$, $12 \mathrm{mg} \cdot \mathrm{mL}^{-1}$ and $\left.40^{\circ} \mathrm{C}\right)$, data taken from the DSC curves.

\begin{tabular}{|c|c|c|c|c|c|c|}
\hline PHBV & $\mathrm{T}_{\mathrm{g}}\left({ }^{\circ} \mathrm{C}\right)$ & $\mathrm{T}_{\mathrm{m}}\left({ }^{\circ} \mathrm{C}\right)$ & $\mathrm{T}_{\mathrm{c}}\left({ }^{0} \mathrm{C}\right)$ & $\Delta \mathbf{H}_{\mathrm{c}}\left(\mathrm{J} \cdot \mathrm{g}^{-1}\right)$ & $\Delta \mathbf{H}_{\mathrm{m}}\left(\mathrm{J} \cdot \mathrm{g}^{-1}\right)$ & $\% \mathrm{C}$ \\
\hline Raw & -5.44 & 166.17 & 51.79 & -36.77 & 52.07 & 35.66 \\
\hline Purified & -10.41 & 152.07 & 51.72 & -26.66 & 47.53 & 32.55 \\
\hline $8 \mathrm{MPa}$ & -2.59 & 164.90 & 54.38 & -22.73 & 63.57 & 43.54 \\
\hline $10 \mathrm{MPa}$ & -3.77 & 165.04 & 48.87 & -6.50 & 51.14 & 35.03 \\
\hline $12 \mathrm{MPa}$ & -1.62 & 166.36 & 52.88 & -19.19 & 51.09 & 34.99 \\
\hline
\end{tabular}

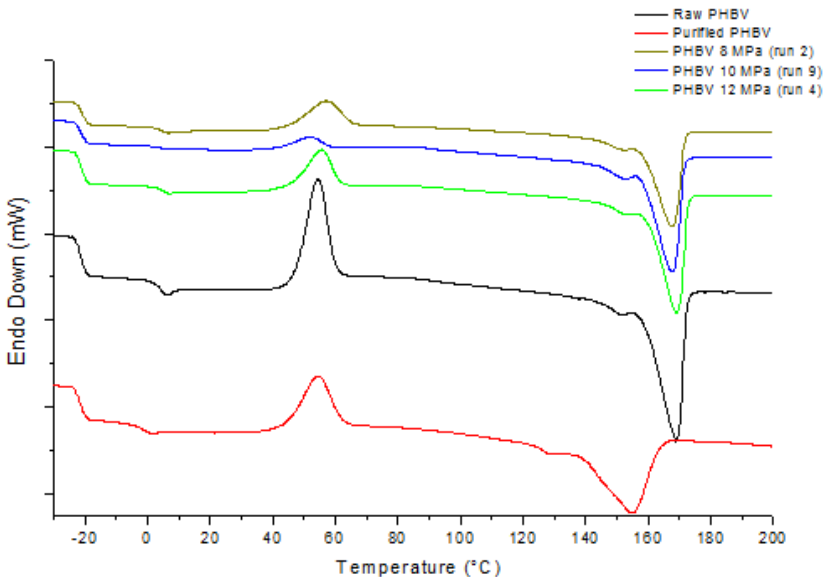

Figure 4. DSC curves of the raw PHBV, purified PHBV and PHBV micronized in runs $2(8 \mathrm{MPa}, 20$ $\mathrm{mg} \cdot \mathrm{mL}^{-1}$ and $\left.35^{\circ} \mathrm{C}\right), 4\left(12 \mathrm{MPa}, 20 \mathrm{mg} \cdot \mathrm{mL}^{-1}\right.$ and $\left.35^{\circ} \mathrm{C}\right)$ and $9\left(10 \mathrm{MPa}, 12 \mathrm{mg} \cdot \mathrm{mL}^{-1}\right.$ and $\left.40^{\circ} \mathrm{C}\right)$.

heating processes and the corresponding thermal parameters are listed in Table 2.

A slight reduction in the glass transition temperature and melting temperature can be observed after PHBV purification, due to the greater mobility of the molecules. The crystallinity degree remained close to $35 \%$, as observed for the raw polymer, after purification and after the supercritical process at 10 and $12 \mathrm{MPa}$. On the other hand, supercritical micronization at $8 \mathrm{MPa}$ resulted in an increase to $43.54 \%$ of crystallinity. The crystallinity degree is estimated based on the polymer melting enthalpy, which is related to the cohesion energy between the chains as well as to the chain flexibility, which affects also the melting entropy. Since this run was performed at lower operation pressure, it might be suggested that the polymeric chains presented a greater level of organization, which would be more difficult to occur in the higher process pressures. This result indicates the possibility of different applications of micronized PHBV, adjusting the process parameters. Considering PHBV use for bioactive compound encapsulation, a lower crystallinity degree would be more interesting, since it promotes easier solubility. However, the fast active compound and polymer co-precipitation via the supercritical antisolvent process hinders chain organization and generally promotes lower crystallinity degree compared to that obtained for single compound micronization (Cocero et al., 2009).

\section{CONCLUSION}

PHBV was successfully micronized by the SEDS technique because particles obtained presented spherical shape, with size from 210 to $720 \mathrm{~nm}$ and practically free from organic solvent, therefore safe for human consumption. These results indicate the application of PHBV for bioactive compound encapsulation and controlled delivery. Since temperature presented a significant positive effect on particle size, the use of lower temperatures is desired due to the smaller particle size produced, lower energetic costs together with less bioactive compound degradation. Moreover, different crystallinity degrees could be obtained according to SEDS operation pressure, which allows different applications of the polymer.

\section{ACKNOWLEDGEMENTS}

The authors thank $\mathrm{CNPq}$ (grant number 478520/2013-1) and CAPES for financial support and scholarships, LCME/UFSC for SEM analyses, Central Analyses of Department of Chemical and Food Engineering for the FTIR and DSC analyses and PHB Industrial S/A for the PHBV supplied.

\section{REFERENCES}

Aguiar, G.P.S., Arcari, B.D., Chaves, L.M.P.C., Magro, C.D., Boschetto, D.L., Piato, A.L., Lanza, M., Oliveira, J.V., Micronization of trans-resveratrol by supercritical fluid: Dissolution, solubility and in vitro antioxidant activity. Ind. Crops Prod. 112, 1-5 (2018). https://doi.org/10.1016/j. indcrop.2017.11.008

Aguiar, G.P.S., Boschetto, D.L., Chaves, L.M.P.C., Arcari, B.D., Piato, A.L., Oliveira, J.V., Lanza, M., Trans-resveratrol micronization by SEDS technique. Ind. Crops Prod. 89, 350-355 (2016). https://doi.org/10.1016/j.indcrop.2016.04.047 
Aguiar, G.P.S., Marcon, M., Mocelin, R., Herrmann, A.P., Chaves, L.M.P.C., Piato, A.L., Lanza, M., Oliveira, J.V. Micronization of N-acetylcysteine by supercritical fluid: Evaluation of in vitro and in vivo biological activity. J. Supercrit. Fluids. 130, 282-291 (2017). https://doi.org/10.1016/j. supflu.2017.06.010

Boschetto, D.L., Dalmolin, I., de Cesaro, A.M., Rigo, A.A., Ferreira, S.R.S., Meireles, M.A.A., Batista, E.A.C., Vladimir Oliveira, J., Phase behavior and process parameters effect on grape seed extract encapsulation by SEDS technique. Ind. Crops Prod. 50, 352-360 (2013). https://doi.org/10.1016/j. indcrop.2013.07.044

Boutin, O., Badens, E., Carretier, E., Charbit, G., Co-precipitation of a herbicide and biodegradable materials by the supercritical anti-solvent technique. J. Supercrit. Fluids 31, 89-99 (2004). https://doi.org/10.1016/j.supflu.2003.09.013

Brunel, D.G., Pachekoski, W.M., Dalmolin, C., Agnelli, J.A.M., Natural additives for poly (hydroxybutyrate - CO - hydroxyvalerate) - PHBV: effect on mechanical properties and biodegradation. Mater. Res. 17, 1145-1156 (2014). https://doi. org/10.1590/1516-1439.235613

Cardoso, F.A.R., Rezende, R.V.P., Almeida, R.A., Cabral, V.F., Zanoelo, E.F., Noriler, D., Meier, H.F., CardozoFilho, L., A model for precipitation of sub-micrometric particles of PHBV poly(3-hydroxybutyrate-co3-hydroxyvalerate) by supercritical assistedatomization. J. Supercrit. Fluids 97, 88-99 (2015). https://doi.org/10.1016/j.supflu.2014.11.007

Chen, A.-Z., Pu, X.-M., Kang, Y.-Q., Liao, L., Yao, Y.-D., Yin, G.-F., Study of poly(1-lactide) microparticles based on supercritical $\mathrm{CO} 2$. J. Mater. Sci. Mater. Med. 18, 2339-2345 (2007). https://doi.org/10.1007/s10856-007-3173-8

Chen, G.-Q., Wu, Q., The application of polyhydroxyalkanoates as tissue engineering materials. Biomaterials 26, 6565-6578 (2005). https://doi.org/10.1016/j.biomaterials.2005.04.036

Cheng, M.-L., Sun, Y.-M., Relationship between free volume properties and structure of poly(3hydroxybutyrate-co-3-hydroxyvalerate) membranes via various crystallization conditions. Polymer 50, 5298-5307 (2009). https://doi.org/10.1016/j. polymer.2009.09.035

Cocero, M.J., Ferrero, S., Crystallization of $\beta$-carotene by a GAS process in batch Effect of operating conditions. J. Supercrit. Fluids 22, 237-245 (2002). https://doi.org/10.1016/S0896-8446(01)00125-5

Cocero, M.J., Martín, Á., Mattea, F., Varona, S., Encapsulation and co-precipitation processes with supercritical fluids: Fundamentals and applications. J. Supercrit. Fluids, 20th Year Anniversary Issue of the Journal of Supercritical Fluids 47, 546-555 (2009). https://doi.org/10.1016/j. supflu.2008.08.015
Costa, M.S., Duarte, A.R.C., Cardoso, M.M., Duarte, C.M.M., Supercritical antisolvent precipitation of PHBV microparticles. Int. J. Pharm. 328, 72-77 (2007). https://doi.org/10.1016/j.ijpharm.2006.08.004

Dal Magro, C., Aguiar, G.P.S., Veneral, J.G., dos Santos, A.E., de Chaves, L.M.P.C., Oliveira, J.V., Lanza, M., Co-precipitation of trans-resveratrol in PHBV using Solution Enhanced Dispersion by Supercritical Fluids technique. J. Supercrit. Fluids. 127, 182-190 (2017). https://doi.org/10.1016/j. supflu.2017.03.025

Fleming, O.S., Kazarian, S.G., Polymer Processing with Supercritical Fluids, in: Kemmere, ir artje F., Meyer, M.T. (Eds.), Supercritical Carbon Dioxide. WileyVCH Verlag GmbH \& Co. KGaA, pp. 205-238 (2005). https://doi.org/10.1002/3527606726.ch10

Franceschi, E., De Cesaro, A.M., Feiten, M., Ferreira, S.R.S., Dariva,C., Kunita,M.H., Rubira,A.F., Muniz, E.C., Corazza, M.L., Oliveira, J.V.,, Precipitation of $\beta$-carotene and PHBV and co-precipitation from SEDS technique using supercritical CO2. J. Supercrit. Fluids 47, 259-269 (2008). https://doi. org/10.1016/j.supflu.2008.08.002

Franceschi, E., De Cesaro, A.M., Ferreira, S.R.S., Vladimir Oliveira, J., Precipitation of $\beta$-carotene microparticles from SEDS technique using supercritical CO2. J. Food Eng. 95, 656-663 (2009). https://doi.org/10.1016/j.jfoodeng.2009.06.034

Kalani, M., Yunus, R., Application of supercritical antisolvent method in drug encapsulation: a review. Int. J. Nanomedicine 6, 1429-1442 (2011). https:// doi.org/10.2147/IJN.S19021

Loss, R.A., Pereira, G.N., Boschetto, D.L., Aguiar, G.S.P., Machado, J.R., Chaves, L.M.P.C., Silva, M.J.A., Oliveira, D., Oliveira, J.V., Encapsulation of eugenyl acetate in PHBV using SEDS technique and in vitro release evaluation. J. Food Sci. Technol. 53，3859-3864 (2016). https://doi.org/10.1007/ s13197-016-2362-1

Machado Jr, F.R.S., Reis, D.F., Boschetto, D.L., Burkert, J.F.M., Ferreira, S.R.S., Oliveira, J.V., Burkert, C.A.V., Encapsulation of astaxanthin from Haematococcus pluvialis in PHBV by means of SEDS technique using supercritical CO2. Ind. Crops Prod. 54, 17-21 (2014). https://doi. org/10.1016/j.indcrop.2014.01.007

Oliveira, L.M., Araújo, E.S., Guedes, S.M.L., Gamma irradiation effects on poly(hydroxybutyrate). Polym. Degrad. Stab. 91, 2157-2162 (2006). https:// doi.org/10.1016/j.polymdegradstab.2006.01.008

Priamo, W.L., Dalmolin, I., Boschetto, D.L., Mezzomo, N., Ferreira, S.R.S., Oliveira, J.V. de, 2013. Micronization processes by supercritical fluid technologies: a short review on process design (2008-2012),Acta Sci. Technol. 35, 695709 (2013). https://doi.org/10.4025/actascitechnol. v35i4.18819 
Priamo, W.L., de Cezaro, A.M., Ferreira, S.R.S., Oliveira, J.V., Precipitation and encapsulation of $\beta$-carotene in PHBV using carbon dioxide as anti-solvent. J. Supercrit. Fluids 54, 103-109 (2010) . https://doi.org/10.1016/j. supflu.2010.02.013

Walkey, C.D., Chan, W.C.W., Understanding and controlling the interaction of nanomaterials with proteins in a physiological environment. Chem. Soc. Rev. 41, 2780-2799 (2012). https://doi. org $/ 10.1039 / \mathrm{c} 1 \mathrm{cs} 15233 \mathrm{e}$

Yeo, S.-D., Kiran, E., Formation of polymer particles with supercritical fluids: A review. J.
Supercrit. Fluids 34, 287-308 (2005). https://doi. org/10.1016/j.supflu.2004.10.006

Yu, H.-Y., Qin, Z.-Y., Surface grafting of cellulose nanocrystals with poly(3-hydroxybutyrate-co-3hydroxyvalerate). Carbohydr. Polym. 101, 471-478 (2014). https://doi.org/10.1016/j.carbpol.2013.09.048 Yu, H.-Y., Qin, Z.-Y., Sun, B., Yang, X.-G., Yao, J.-M., Reinforcement of transparent poly(3hydroxybutyrate-co-3-hydroxyvalerate) by incorporation of functionalized carbon nanotubes as a novel bionanocomposite for food packaging. Compos. Sci. Technol. 94, 96-104 (2014). https:// doi.org/10.1016/j.compscitech.2014.01.018 